\title{
Techniques for Modelling and Optimizing the Mechanical Properties of Natural Fiber Composites: A Review
}

\author{
Timothy K. Mulenga (D), Albert U. Ude* ${ }^{(D)}$ and Chinnasamy Vivekanandhan \\ Department of Mechanical, Energy and Industrial Engineering, Faculty of Engineering and Technology, \\ Botswana International University of Science and Technology, 10071 Palapye, BW, Botswana; \\ timothy.mulenga@studentmail.biust.ac.bw (T.K.M.); chinnasamyv@biust.ac.bw (C.V.) \\ * Correspondence: udea@biust.ac.bw; Tel.: +267-7595-7014
}

check for updates

Citation: Mulenga, T.K.; Ude, A.U.; Vivekanandhan, C. Techniques for Modelling and Optimizing the Mechanical Properties of Natural Fiber Composites: A Review. Fibers 2021, 9, 6. https://doi.org/10.3390/ fib9010006

Received: 11 September 2020 Accepted: 18 November 2020 Published: 14 January 2021

Publisher's Note: MDPI stays neutral with regard to jurisdictional clai$\mathrm{ms}$ in published maps and institutional affiliations.

Copyright: $@ 2021$ by the authors. Licensee MDPI, Basel, Switzerland. This article is an open access article distributed under the terms and conditions of the Creative Commons Attribution (CC BY) license (https:// creativecommons.org/licenses/by/ $4.0 /)$.

\begin{abstract}
The study of natural fiber-based composites through the use of computational techniques for modelling and optimizing their properties has emerged as a fast-growing approach in recent years. Ecological concerns associated with synthetic fibers have made the utilisation of natural fibers as a reinforcing material in composites a popular approach. Computational techniques have become an important tool in the hands of many researchers to model and analyze the characteristics that influence the mechanical properties of natural fiber composites. This recent trend has led to the development of many advanced computational techniques and software for a profound understanding of the characteristics and performance behavior of composite materials reinforced with natural fibers. The large variations in the characteristics of natural fiber-based composites present a great challenge, which has led to the development of many computational techniques for composite materials analysis. This review seeks to infer, from conventional to contemporary sources, the computational techniques used in modelling, analyzing, and optimizing the mechanical characteristics of natural fiber reinforced composite materials.
\end{abstract}

Keywords: natural fiber; composite; hybrid; computational techniques; mechanical properties

\section{Introduction}

The world has witnessed an exponential growth in computational power coupled with improved algorithms in the past two decades. To this end, researchers from different backgrounds are implementing the available computational methods to carry out analytical studies to achieve advanced design requirements. Modelling and optimization techniques are used by computational engineers to address the physical complexities that are encountered in science and engineering research. Researchers in the field of material science are exploring the utilization of these computational methods to model and optimize the different characteristics of composite materials reinforced with natural fibers with the aim of potentially replacing the synthetic fibers because of sustainability issues and environmental aspects.

Natural fibers have become popular due to their promising properties such as high strength to weight ratios, low densities, inexpensiveness, acceptable mechanical properties, environmental friendliness, ease of manufacturing and availability [1-12]. However, poor properties associated with natural fibers, such as high water absorption, poor bonding, low durability, as well as low mechanical and thermal properties when compared to synthetic fibers limit their industrial applications [13-17]. Numerous methods have been developed to overcome these limitations which include fiber treatment, addition of nano-fillers and hybridization. The adoption of these methods in recent years to develop natural fiber composite (NFC) materials has widened their area of application including structural, household, aerospace, sporting, automobile, and other industrial applications [2,14,18-22].

The process of analyzing the quality of natural fibers and their resulting composites is complex and thus causes difficulties in the development of generic methods that can 
be utilized to model and optimize the properties of composites. The adoption of current available computational techniques for analyzing the properties of NFCs has proven beneficial in the process of modelling and optimizing the composite materials [23-26]. The use of computational or mathematical models enables researchers and manufacturers to easily find the optimal combination of constituent materials to balance strength and cost of the resulting materials. The modelling of composite material involves analyzing the relationship between the input and output parameters in materials processing. On the other hand, the optimization process involves the processing of the output parameters which requires first the determination of the relationship between process parameters and subsequent optimization of the output parameters using an appropriate optimization algorithm $[27,28]$.

Different modelling and optimization methods of natural fiber composites include finite element analysis (FEA) [29-31], artificial neural networks (ANN) [28,29], and rule of hybrid mixture (RoHM) [31-34]. Numerous literatures are available on the utilization of computational techniques in the modeling and optimization of composite materials in the field of science and engineering. The hardness, tensile strength, wear rate, impact strength, elasticity, and fatigue are some of the known composite material properties modeled and optimized [35-43].

\section{Natural Fiber Composites}

Composite materials have proved pivotal to the manufacturing industries due to the ability to tailor and enhance its properties to desire. Properties such as, strong damping capacity, high corrosion resistance, high specific strength and flexural modulus have been enhanced in recent years to compete with some conventional materials [1,43]. Natural fiber composites have found attraction in composite materials as a reinforcing phase due to their unique characteristics such as high impact strength, environmental friendliness, and low densities $[44,45]$. As a reinforcement material in composites, natural fibers serve the purpose of providing strength and stiffness to the composite material thus improving the mechanical characteristics of the resulting composite. The reinforcing fibers can either be fibrous or non-fibrous (particulates) in nature. Some natural fibers like sisal, kenaf, banana, coir and jute which are usually classified according to their fiber sources, have found attraction for application in consumer goods, civil engineering, and other industrial applications [44]. Table 1 depicts the various applications of known cellulose-based materials.

Table 1. Different applications of cellulose-based materials [21,44].

\begin{tabular}{|c|c|c|}
\hline Cellulose Materials & Application Industries & Example: Application Areas \\
\hline $\begin{array}{l}\text { Hemp, Oil palm, Wood, Flax, Rice husk, } \\
\text { Bagasse, Sisal, Stalk, Coconut, Bamboo }\end{array}$ & Construction/Civil & $\begin{array}{ll}- & \text { Window/Door frame } \\
- & \text { Roofing } \\
- & \text { Panels } \\
- & \text { Pipelines } \\
- & \text { Bricks }\end{array}$ \\
\hline Flax, Coir, Hemp, Jute, Sisal, Kenaf & Automobile & $\begin{array}{ll}- & \text { Car roof } \\
- & \text { Door handles } \\
- & \text { Dashboard } \\
- & \text { Door panels }\end{array}$ \\
\hline Kenaf, Flax, Sisal & Aerospace & $\begin{array}{ll}- & \text { Interior cabin } \\
- & \text { Secondary structures } \\
- & \text { Blade }\end{array}$ \\
\hline Hemp, Cellulose & Electronics & $\begin{array}{ll}- & \text { Sensors } \\
- & \text { Energy storage units } \\
- & \text { Coatings } \\
- & \text { Circuit componets }\end{array}$ \\
\hline
\end{tabular}


Table 1. Cont.

\begin{tabular}{|c|c|c|}
\hline Cellulose Materials & Application Industries & Example: Application Areas \\
\hline $\begin{array}{l}\text { Nanoclay, Rice } \\
\text { husk, Ramie }\end{array}$ & Packaging & $\begin{array}{ll}\text { - } & \text { Marine packaging } \\
\text { - } & \text { Reusable packaging } \\
\text { - } & \text { Degradable packaging } \\
\text { - } & \text { Packing with recycled content }\end{array}$ \\
\hline $\begin{array}{l}\text { Lignin nanoparticles, Hydroxyapatite } \\
\text { (HA)/collagen alginate, Xyloglucan, }\end{array}$ & Biomedical & $\begin{array}{ll}- & \text { Tissue engineering } \\
- & \text { Drug delivery } \\
- & \text { Gene therapy }\end{array}$ \\
\hline Flax & Sports & $\begin{array}{ll}\text { - } & \text { Tennis racket } \\
\text { - } & \text { Bicycle frame }\end{array}$ \\
\hline $\begin{array}{l}\text { Hemp, Kenaf, Cotton, Coir, Ramie, } \\
\text { Coconut, Bamboo }\end{array}$ & Household & $\begin{array}{ll}- & \text { Textile } \\
- & \text { Home furnishing }\end{array}$ \\
\hline
\end{tabular}

These natural fibers are embedded in a matrix material which serves the purpose of holding the fibers in their set place and essentially transferring the stress load to the fibers. The matrix material also functions to govern the resulting composite surface appearance, overall durability, shape, and environmental tolerance [46]. Matrix materials are also categorized into thermoset and thermoplastics to which thermoplastics are favored over thermosets because of their ease of moldability into various shapes.

\section{Mechanical Properties of Natural Fiber Composites}

Different parameters have been identified as being responsible for the diverse mechanical characteristics observed in natural fiber composite. These parameters include fiber length, fiber weight ratio, fiber orientation, fiber selection, matrix selection, fabrication process, and interfacial interaction between fiber and matrix [47,48]. Presently, most natural fiber composites have inferior mechanical properties compared to their synthetic counterparts. In view of this limitation, methods like natural fiber hybridization and composite constituent optimization have been employed to address this deficit. In a hybrid composite, two or more dissimilar fibers are fused together in a single matrix to form a composite panel. Hybridization can also be achieved by combining varying lengths and diameters of dissimilar short fibers, this approach has substantially improved the mechanical properties of natural fiber composites [49]. The addition of nano-filler content is also used to overcome the limitation of composite materials reinforced with natural fibers in order to obtain improved dimensional stability/interfacial bonding as well as mechanical and thermal properties [49,50]. Abundant literature is available on mechanical behavior and performance of composite materials reinforced with natural fibers. Listed in Table 2 are some of the natural fiber reinforced composite materials and their corresponding mechanical properties obtained from various studies. 
Table 2. List of some natural fiber composites and their mechanical properties.

\begin{tabular}{|c|c|c|c|c|c|c|}
\hline Fiber & Matrix & $\begin{array}{c}\text { Tensile Strength } \\
(\mathrm{MPa})\end{array}$ & $\begin{array}{l}\text { Stiffness } \\
\text { (GPa) }\end{array}$ & $\begin{array}{c}\text { Flexural Strength } \\
(\mathrm{MPa})\end{array}$ & $\begin{array}{l}\text { Flexural Modulus } \\
\text { (GPa) }\end{array}$ & Reference \\
\hline Banana & Epoxy & 46 & 8 & - & - & [1] \\
\hline Sisal & Epoxy & 212 & 6 & 320 & 27 & [51] \\
\hline Oil Palm & $\mathrm{PP}$ & 53 & 2 & 80 & 3 & [52] \\
\hline Jute & PP & 74 & 11 & 112 & 12 & [53] \\
\hline Coir & Epoxy & 225 & 6 & - & - & [52] \\
\hline Kenaf & PLA & 223 & 23 & 259 & 22 & [54] \\
\hline Coir & $\mathrm{PP}$ & 17 & 2.3 & 27.4 & 1.8 & [55] \\
\hline Hemp & Epoxy & 165 & 17 & 180 & 9 & [52] \\
\hline Sisal/Hemp & PLA & 60.23 & 6.1 & 79.76 & 6.04 & [56] \\
\hline Flax & UP & 147 & 14 & 198 & 17 & [52] \\
\hline Jute/Banana & Epoxy & 18.96 & 0.724 & 59.84 & 9.170 & [57] \\
\hline Jute/Sisal & Epoxy & 74.78 & 6.76 & - & - & [58] \\
\hline Hemp & $\mathrm{PP}$ & 52 & 4 & 86 & 4 & [53] \\
\hline Flax & Epoxy & 160 & 15 & 190 & 18 & [52] \\
\hline
\end{tabular}

\section{Modelling and Optimization of Mechanical Properties of Natural Fiber Composites}

Numerous theories of composite fiber reinforcements have been developed over the years to interpret different properties of fiber reinforced composites since the industrialization age. These theoretical models have gained attraction in research because of their advantages in reducing time spent on conducting experiments. Simulation techniques enable researchers to analyze complex natural phenomena and processes, which would otherwise be very difficult to carry out $[59,60]$. Modelling the mechanical properties of reinforced natural fiber composite materials is considered a very complex process due to varying parameters, such as the type of matrix and fiber used, overall composition, manufacturing process, and intended applications [23].

For this purpose, several theories have been proposed for modelling and analyzing the characteristics of short, long and varying oriented fiber composites [59]. These modelling theories are based on different characteristics of materials which include physical, chemical, thermal, and mechanical properties. The exceptional improvement in computational power in recent years has enabled researchers to develop these enhanced modelling approaches with increased precision. This work aims to review some of these computational modelling approaches used in the analysis of fiber reinforced composite materials.

\subsection{Rule of Mixture/Rule of Hybrid Mixture}

Venkateshwaran et al. [44] described the Rule of Hybrid Mixture (RoHM) as a model that considers a hybrid composite as a structure made up of more than one single fiber embedded in a common matrix material. Applying the iso-strain state condition to a hybrid composite reinforced with two fibers yields Equation (1), where $\varepsilon_{h c}, \varepsilon_{f 1}, \varepsilon_{f 2}$ denote the overall material strain, first fiber strain and second fiber strain, respectively. By assuming no interplay between the single fibers, the RoHM equation is developed to compute modulus of the hybrid composite shown in Equation (2), where $E_{h c}, V_{c 1}$, and $V_{c 2}$ denote the elasticity of the hybrid composite and relative hybrid volume fraction of the first and second fiber composite, respectively.

$$
\begin{gathered}
\varepsilon_{h c}=\varepsilon_{f 1}+\varepsilon_{f 2} \\
E_{h c}=E_{c 1} V_{c 1}+E_{c 2} V_{c 2}
\end{gathered}
$$

It is worth mentioning that Equations (1) and (2) will only hold under the following conditions; $V_{c 1}+V_{c 2}=1, V_{C 1}=V_{f 1} / V_{t}, V_{C 2}=V_{f 2} / V_{t}$ and $V_{t}=V_{f 1}+V_{f 2}$ where $V_{t}$ is the overall reinforcement volume fraction upon the inclusion of $\left(V_{f 1}+V_{f 2}\right)$ which is essentially used as the reinforcement volume fraction for the computation of the elasticity ( $E_{c 1}$ and $E_{c 2}$ ) of both the exclusive composites [44]. RoM/RoHM models have been successfully 
used in the past to accurately model and predict the tensile characteristics of unidirectional, continuous fiber composites [44]. Venkateshwaran et al. [44] reported the tensile strength and modulus of banana/sisal fiber hybrid composites in varying ratios by carrying out experiments and also applying the RoHM as a prediction tool. By keeping the overall fiber volume fraction fixed, their results revealed a great similarity between the actual experimental results and the RoHM results as depicted in Figures 1 and 2 allowing to conclude that the two methods were in good agreement.

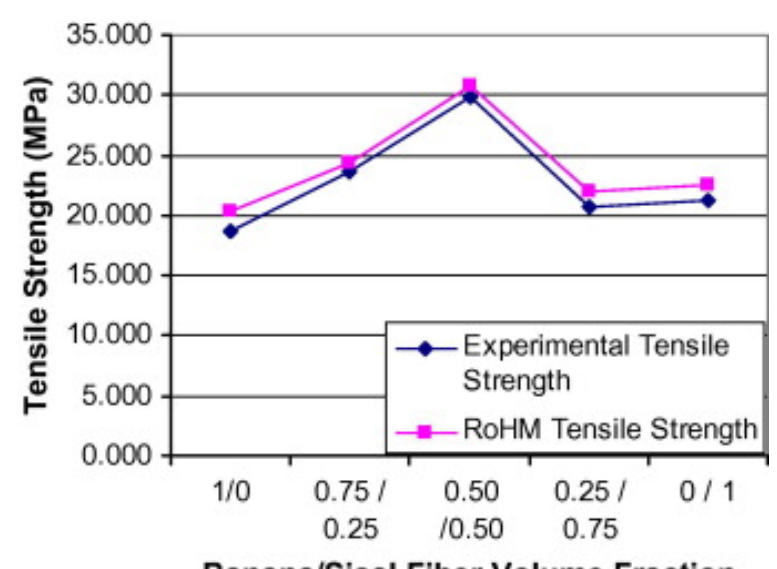

Figure 1. Experimental and RoHM tensile strength results of Banana/Sisal fiber composite (Venkateshwaran et al. [44]) Reproduced with permission from [Venkateshwaran, N; Elayaperumal, A; Sathiya, G.K.], [Prediction of tensile properties of hybrid-natural fiber composites]; published by [Elsevier: Materials Today], [2012].

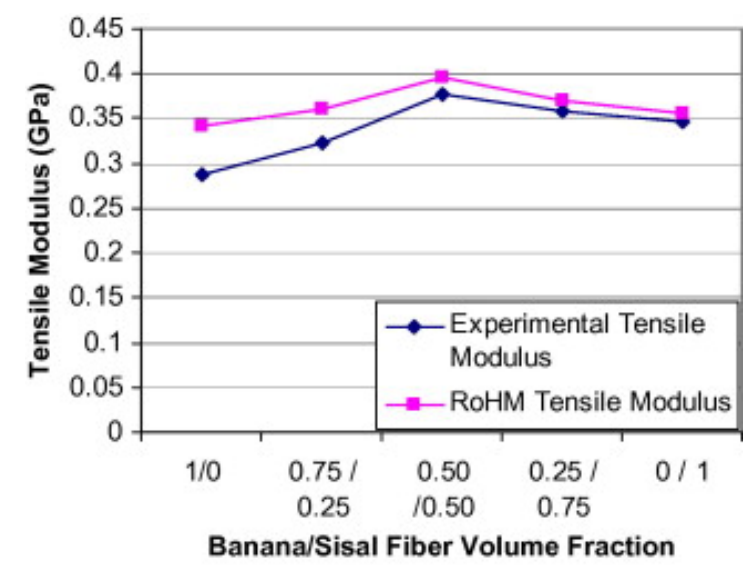

Figure 2. Experimental and RoHM tensile modulus results of Banana/Sisal fiber composite (Venkateshwaran et al. [44]) Reproduced with permission from [Venkateshwaran, N; Elayaperumal, A; Sathiya, G.K.], [Prediction of tensile properties of hybrid-natural fiber composites]; published by [Elsevier: Materials Today], [2012].

\subsection{Halpin-Tsai Model}

Based on mathematical modelling, Halpin-Tsai model is employed to predict the elastic modulus of a composite material using the fiber orientation, geometry and elasticity of fiber and matrix material as input parameters [61,62]. Although often considered to be an empirical approach, the self-consistent field approach forms the basis of this model. The model proposes that the tensile modulus and strength of a composite material in study be given by Equations (3) and (4) where $E_{c}, E_{m}, T_{m}$, and $T_{c}$ denote the elastic moduli of the composite, elastic moduli of matrix, tensile strength of matrix, and tensile strength of composite, respectively. $V_{f}$ denote the volume fraction of fiber in the composites 
while the value parameter of $A$ is obtained from Einstein coefficient $K$ which is given by $A=K-1$ and $K=1+2 l / d$ where the fiber diameter and length are denoted $d$ and $l$, respectively. The parameter $\eta$ is given by Equations (5) and (6) while the parameter $A$ is the measure of fiber geometry, fiber distribution and fiber loading conditions. $E_{f}$ and $T_{f}$ denote the elastic moduli and tensile strength of the fiber, respectively. Ebrahimi et al. [62] successfully investigated for the first time the analysis of the natural vibration limitation of hybrid nanocomposites. The Halpin-Tsai model's governing equations were used to solve the problem analytically in order to acquire the natural frequency of the structure's oscillation. The numerical results obtained after carrying out optimisation revealed that higher frequencies can be attained by hybrid nanocomposites when compared to nonhybrid composites.

$$
\begin{gathered}
E_{c}=E_{m}\left[\frac{1+A \eta V_{f}}{1-\eta V f}\right] \\
T_{c}=T_{m}\left[\frac{1+A \eta V_{f}}{1-\eta V f}\right] \\
\eta=\frac{E_{f} / E_{m}-1}{E_{f} / E_{m}+A} \\
\eta=\frac{T_{f} / T_{m}-1}{T_{f} / T_{m}+A}
\end{gathered}
$$

\subsection{Hirsch Model}

This model is concerned with the stacking sequence and orientation of fiber in a matrix material [61]. A schematic diagram of the model is depicted in Figure 3 which shows a mixture of parallel and series models. Equation (5) is employed to govern the characteristics of the composite where $T_{c}, T_{m}$ and $T_{f}$ denote tensile strength of the composite, tensile strength of matrix material and the tensile strength of the fibers, respectively, while $V_{m}$ represents the volume fraction of the matrix and $V_{f}$ represents the fiber volume fraction.

$$
T_{c}=x\left(T_{m} V_{m}+T_{f} V_{f}\right)+(1-x) \frac{T_{f} T_{m}}{T_{m} V_{f}+T_{f} V_{m}}
$$

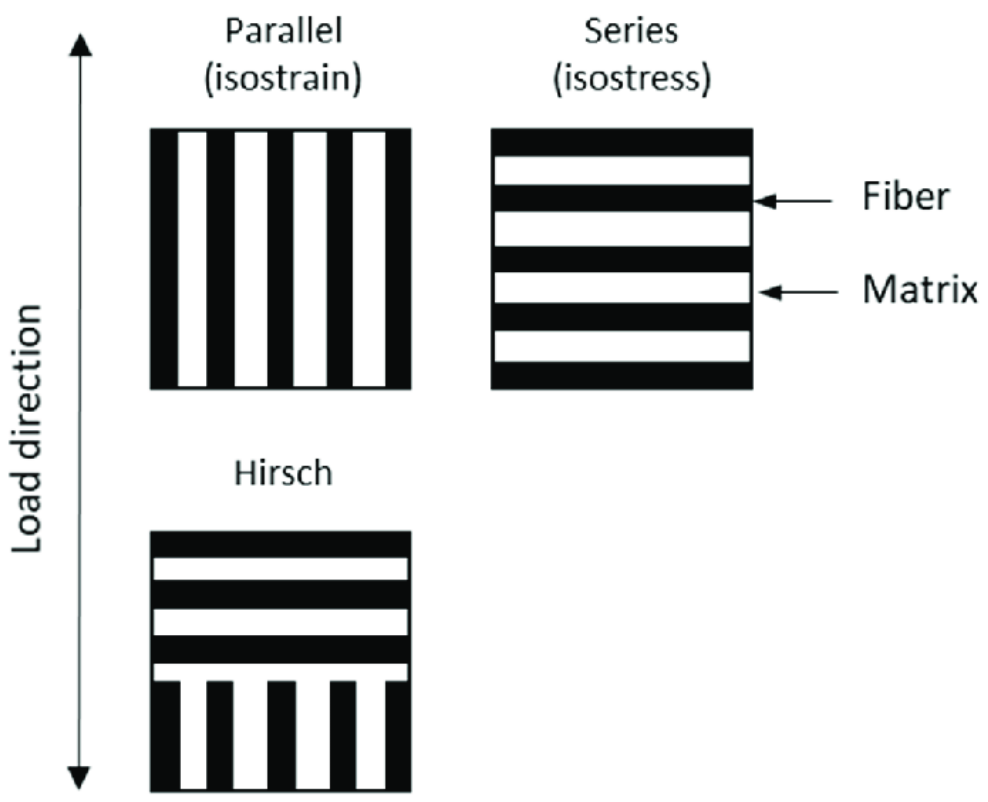

Figure 3. Schematic diagram of Hirsch model (Krishnan et al. [62]) Reproduced with permission from [Krishnan, K.A.; Anjana, R.; George, K.], [Effect of alkali-resistant glass fiber on polypropylene/polystyrene blends: Modeling and characterization]; published by [Wiley: Polymer Composites], [2014]. 
The $x$ in the equation represents a variable which gives the load transfer between the matrix and fiber [61]. Arrakhiz et al. [63] reported the fabrication and characterization of luffa/glass fiber polyester hybrid composite material. The Hirsch model was used to better describe the tensile characteristics of the hybrid composite which revealed the mechanical performance of this hybrid composite to be adjustable between the values of 0.37 and 0.55 .

\subsection{Modified Bowyer and Bader's Model}

Modified Bowyer and Bader's is a mathematical model developed to analyze the tensile modulus and strength of a given composite material [61]. Based on this model, the tensile strength of short fiber-reinforced thermoplastic composites is the sum of contributions from subcritical and supercritical fibers and that from the matrix. The equation governing the model is given by Equations (6) and (7) where the fiber orientation factor (ranging from 0 to 1 ) is denoted $K_{1}$ while the fiber length factor is denoted with $K_{2}$ and is given by $K_{2}=(l-l c) / 2 l$ forl $>l c$ or $K_{2}=l c / 2 l$ forl $<l c$ where the fiber length and critical length are denoted $l$ and $l c$, respectively. $T_{c}, T_{m}, E_{c}, E_{f}, V_{m}$, and $T_{f}$ denote the tensile strength of the composite, tensile strength of the matrix, elastic moduli of the composite, elastic moduli of the fiber, volume fraction of the matrix and tensile strength of the fiber.

$$
\begin{aligned}
& T_{c}=T_{f} K_{1} K_{2}+T_{m} V_{m} \\
& E_{c}=E_{f} K_{1} K_{2}+T_{m} V_{m}
\end{aligned}
$$

Venkateshwaran et al. [61] carried out a study to develop a hybrid composite by using epoxy matrix reinforced with short banana-glass fiber and compared the investigational results of the tensile strength obtained from their experiment with those of the theoretical model. The Bowyer-Bader model was employed to predict the tensile strength values that were much closer to those obtained from experiment.

\subsection{Continuum Theory}

Based on Continuum mechanics, this theory uses the non-equilibrium thermodynamic concept to methodologically investigate the effect of different degradation on the mechanical behavior of materials [39]. Natural fiber-based composites applied in moist environments involve interaction between the elastic and inelastic deformation, water diffusion and progressive damage. The Continuum Damage Mechanics, (CDM), introduces numerous constitutive degradation models that aim to relate the mechanical damages of fiber-based composites. Helmholtz free energy formulation of a material can be assumed as in Equation (8) for an isothermal deformation and water absorption processes where Ć denote the modified right Cauchy-Green deformation tensor and $C_{\alpha}$ is given by Equation (11). The parameters $C_{\alpha}, J$ and $v$ represent the molar concentration of water molecules in the composite, volume ratio of the fiber and material parameter, respectively. The influence of damages induced by external loadings and water, can be described by introducing two internal variables, denoted as $\alpha_{1}$ and $\alpha_{2}$, respectively [39].

$$
\begin{gathered}
\psi=\psi\left(\dot{C}_{,}, C_{\alpha}, \alpha_{1}, \alpha_{2}\right) \\
C_{\alpha}=\frac{J-1}{v}
\end{gathered}
$$

To formulate the constitutive equations, the Helmholtz free energy function is decomposed into two parts being the mechanical energy caused by deformation and the chemical energy by water diffusion [39] given in Equation (12).

$$
\psi=\psi\left(\dot{\mathbf{C}}, C_{\alpha}, \alpha_{1}, \alpha_{2}\right)=\varphi_{\text {mech }}\left(\dot{C}, C_{\alpha}, \alpha_{1}, \alpha_{2}\right)+\varphi_{\text {diff }}\left(C_{\alpha}\right)
$$

Based on the continuum theory it is possible to report the degradation caused by water absorption in short or long natural fiber-based composites by establishing an internal 
parameter to propose a constitutive degradation model [64]. Some researchers such as Tian and Zhong [65] have also been able to expand the application of these models to predict long-term mechanical behavior of unidirectional natural fiber-based composite under hygrothermal ageing. Tian et al., [65] investigated the mechanical performance of composites materials reinforced with natural fibers by applying the phenomenological damage mode to report the mechanical performance of the composite when taking into account the integrated measures of external loading and water absorption. From the results of their work, the continuum theory was employed to predict the tensile strength and elasticity due to water absorption with time to which the theoretical values were observed to be in good agreement with the corresponding experimental values. They have since been able to conclude that the results obtained are evidence of the continuous degradation model and thus capable of effectively describing the strength of the material in the course of water absorption in addition to the evolution laws for elasticity. This in turn paves way for theoretical foundations for future applications of composite materials reinforced with natural fibers for use in outdoor load-carrying structures.

\subsection{Finite Element Analysis}

Since its establishment, finite element analysis (FEA) has reigned supreme as computational techniques for modelling and optimization in a variety of engineering disciplines [66]. The most commonly used software tool FEA is the ANSYS engineering simulation and 3D design software. The process of FEA can be broken down into three parts which are: modelling (pre-processing step), analysis and optimization (post processing step). The aims of the pre-processing stage are the 1D, 2D, or 3D modelling of the material, designating appropriate material models, material properties, meshing, elements, and applying proper structural or thermal boundary conditions with the applied loads, such as mechanical and thermal loads [66]. The post processing stage is conducted to compute the response of a material member subjected to any loading such as thermal, impact, static, fatigue before the product development stage [66]. Results obtained from the FEA model are represented in terms of plots, graphs, tables, deflected shapes of members and/or animation. For optimization, a comparison between experimental and theoretical results is conducted. Figure 4 shows sample tensile test results conducted through FEA analysis which is an example of how FEA is utilized to provide an accurate approximation to real performance. Due to its profound results, finite element analysis has found widespread application in different industries, including aerospace, automotive, civil, commercial products, and electronic goods.

As an integral part of the design, FEA has gained interest in the analysis of natural fiber-based composite materials. The mechanical performance of chopped, natural fiber composites with and without closed-cell microcellular foamed structures were studied by Kerna W.T et al. [67] using finite element analysis. The stress-strain properties of analogous test specimens conducted on polypropylene matrix material reinforced with wheat straw fibers were studied using FEA analysis and SEM. The incorporation of wheat straw fiber to polypropylene matrix was found to enable microcellular foaming while the finite element models provided the explanations for the variations in elastic modulus, brittleness, and fiber stress found in the different cases. They have since been able to conclude that the relationship between fiber length effects and microcell effects seems to reduce the effect of fiber length on the overall mechanical behavior which has been confirmed by experimental results on microcellular specimens.

Sowmya C. et al. [68] also achieved agreeing results between the finite element analysis and experimental results after developing a new hybrid composite material using natural fiber as reinforcement material with epoxy and polyester resins. The hybrid composite material was fabricated using jute and hemp fibers along with graphite filler for $30^{\circ}, 45^{\circ}$, and $90^{\circ}$ fiber orientations. FEA was used to compare the tensile, flexural, impact and hardness characteristics obtained from the experimental results. Their results deduced that elongation, tensile strength, flexural strength, impact strength, hardness, and specific 
gravity values were all obtained more at $90^{\circ}$ orientations when compared to $30^{\circ}$ and $45^{\circ}$ orientations, which was in agreement with the finite element analysis conducted.

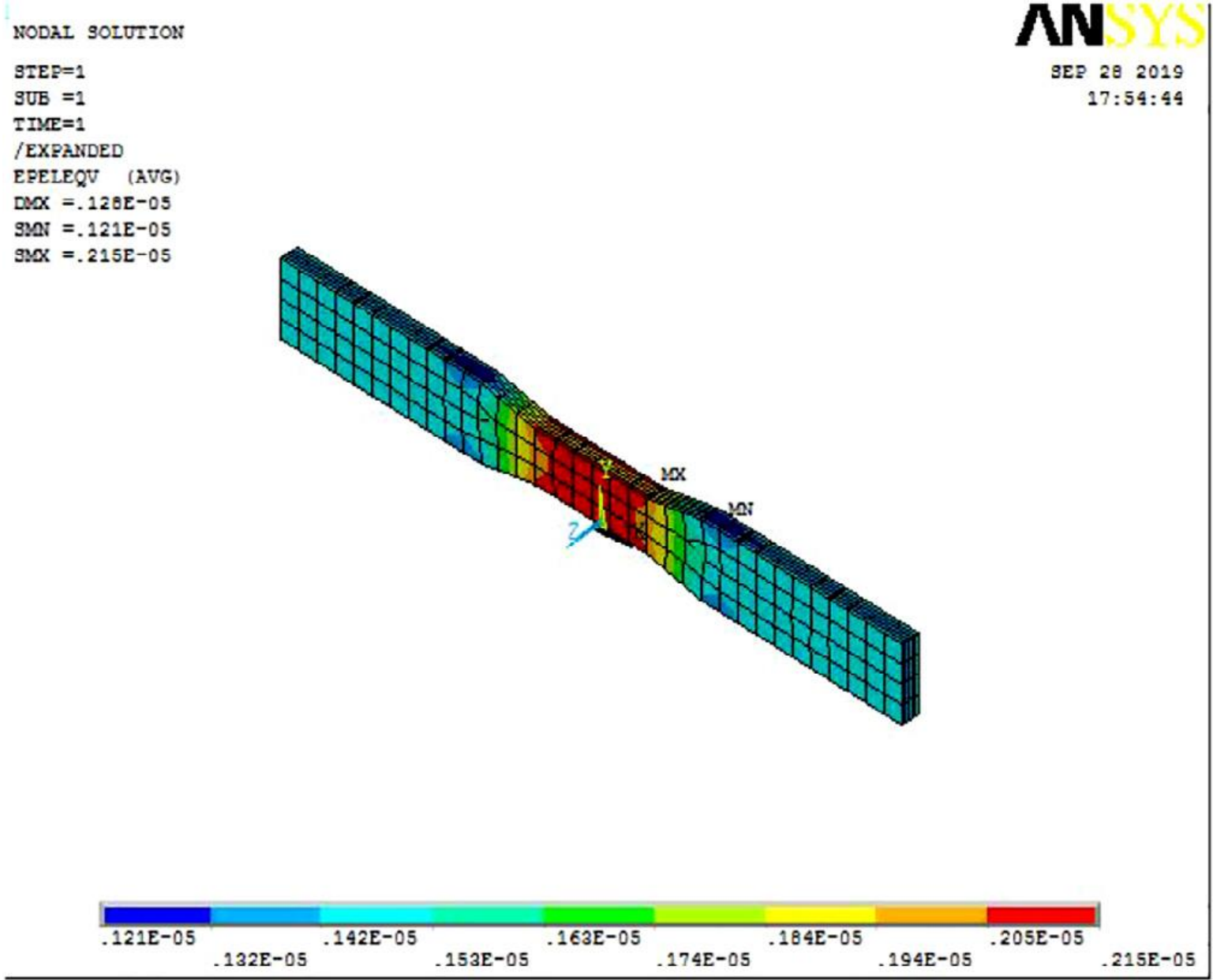

Figure 4. FEA tensile test result (experimental results from Balasubramanian et al., [29]) Reproduced with permission from [K.Balasubramaniana; N.Rajeswarib; K.Vaidheeswarana], [Analysis of mechanical properties of natural fibre composites by experimental with FEA]; published by [Elsevier: Materials Today], [2020].

\subsection{Artificial Intelligence}

Artificial intelligence (AI) is a branch of computer science that is described as the ability of computers to mimic human behavior and is one of the exciting discoveries of the 20th century. AI is able to achieve enormous capabilities by deriving rules and building models by manipulating vast amounts of data with the aim of capturing the underlying information in data to gradually enhance the performance of predictive models and use data to make informed decisions [69]. Several techniques have already been used to analyse fiber reinforced composites, including support vector machines (SVM), decision trees, K-Means, K-nearest neighbor (KNN), naive Bayes, and neural networks (NNs). These techniques are all stochastically driven and each attempts to draw correlations through data by defining different learning tasks. The application of $\mathrm{AI}$ in the manufacturing processes of composite materials is an attempt to address the underlying complexity of their structure which often limits their scope and applicability. Furthermore, artificial intelligence is also being used to automate fabrication of composite materials in order to achieve optimized manufacturing control.

Recently, a computational technique termed machine learning (ML) under the domain of AI has gained interest as an emerging modelling approach. Raschka et al. [70] defined 
ML as the ability of computer programs to make decisions without explicitly being programmed. Three different types of ML exits; supervised learning, unsupervised learning, and reinforcement learning. Supervised learning methods such as logistic regression and classification methods have found attraction as modelling techniques for composite materials [70]. Figure 5 presents a summary of a common supervised learning flowchart in which data that are labeled are passed to a ML model for training to allow the resulting model to make predictions on new and unseen data.

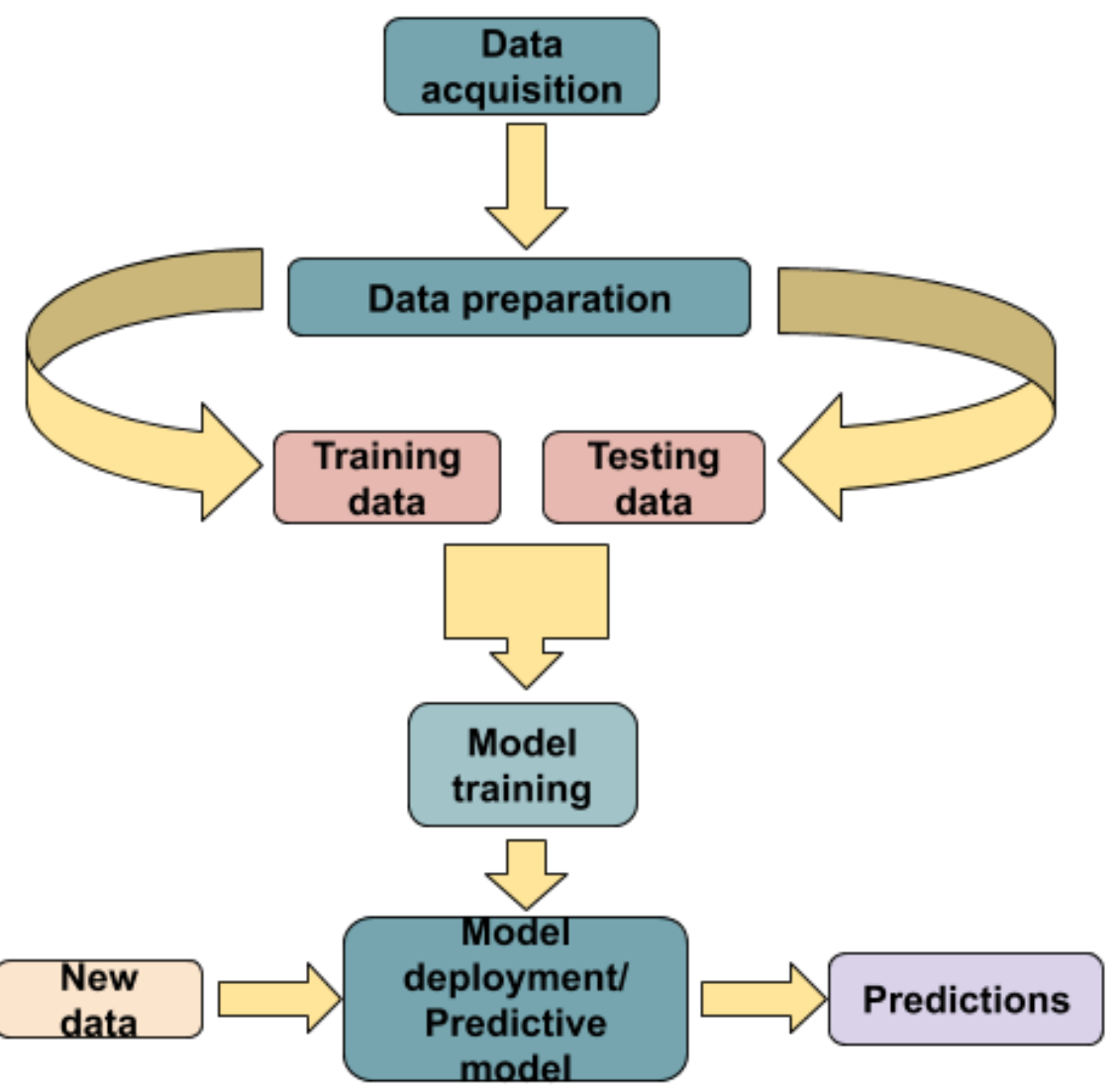

Figure 5. Typical supervised learning workflow.

The logistic and linear regression methods of machine learning are however limited to simple linear problems. Artificial neural networks (ANN), another technique under AI, provides a more robust and complex structure that aims to solve even more complex, non-linear, and dynamic problems. The domain of ANNs under AI is termed deep learning which gained interest as a modelling algorithm in the recent decade. ANNs have attracted the attention of material scientists owing to the improved computational power coupled with high precision that can be achieved from these models [69].

An illustration of a basic neural cell model depicted in Figure 6 which reveals the major elements of an artificial neuron which include the inputs, weights, summation function, activation function and the outputs. The data inputs are denoted $x_{i}$ while the weights are denoted $w_{\mathrm{ij}}$ which emphasize the influence of each input data point. The summation function is denoted net ${ }_{j}$ and computes the net input on a neural cell with some associated bias and the result is fed into an activation function which addresses the nonlinear behavior [69]. 


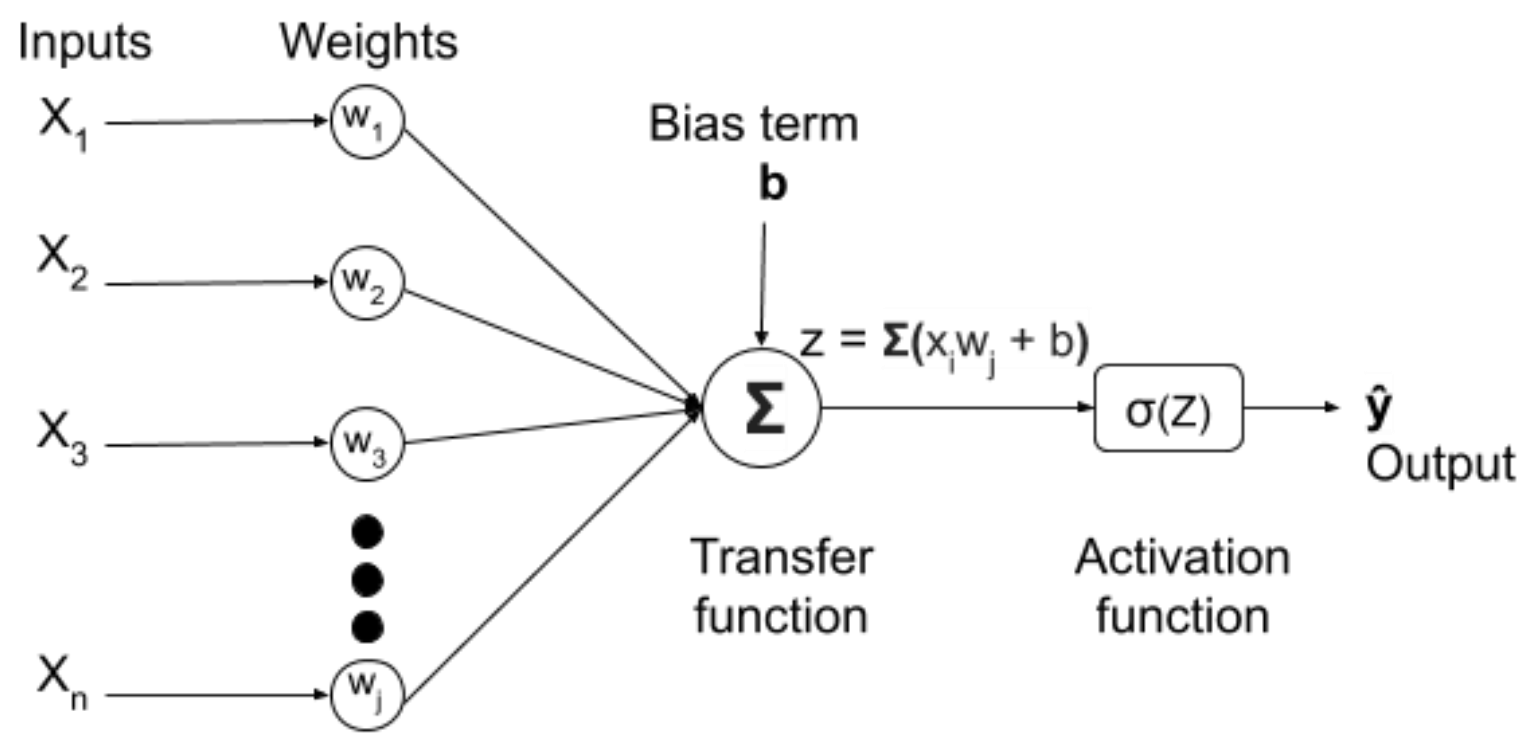

Figure 6. Illustration of an Artificial neural cell.

An example of an ANN architecture is depicted in Figure 7 which is made up of green dots, purple dots and red dots which make up the input nodes, hidden nodes, and output nodes respectively. The signals transverse initially from the first input layer, through the hidden layers and finally out through the output layer with the overall aim of achieving an output result that accurately matches the input parameters [69]. The flow of information between the connected node or neurons is termed the learning phase. The MATLAB software package is commonly used for training and testing the model.
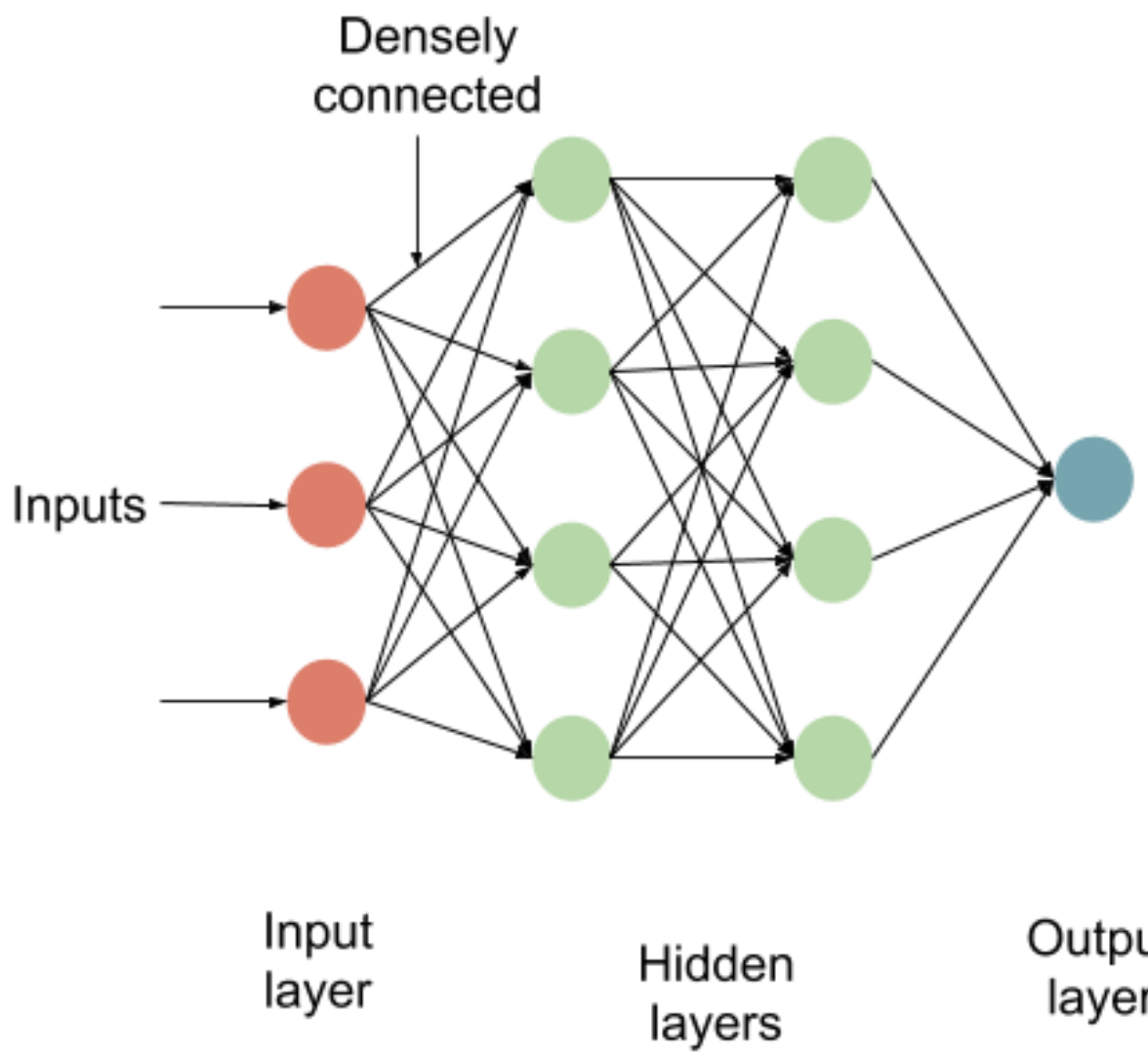

Output

layer

Figure 7. An example of Artificial Neural Network. 
To illustrate an ANN model for predicting properties of a fibre reinforced composite, Figure 8 depicts an ANN model with one input layer and 3 input nodes, two hidden layers with 5 nodes each and one output layer with 3 nodes. The model is designed to predict the density, hardness and tensile strength given the reinforcement content (wt.\%), size (m) and milling time as input parameters. Ang et al. [61] investigated the first-ply failure of glass/epoxy composite pipes by developing an artificial neural network (ANN) model to predict the onset failure of the composite material under multiaxial loadings. By utilizing the inputs and outputs of their experimental data, they trained the model for classification in order to predict the first-ply failure within the composite material under different biaxial stress ratios. To illustrate the failure points, they plotted a biaxial failure envelope in a graph that depicted the axial stress versus hoop stress which depicted closely related plots between experimental and predicted data. Based on their results, their model was able to achieve a mean classification accuracy rate of $95-99.66 \%$ within the range of accuracy. When compared to their experimental results, the (ANN) model's prediction depicted similar results with less than $30 \%$ variation prompting a suggestion that the model can be utilised for useful predictions of onset failure analysis in composite materials under varying stress conditions.

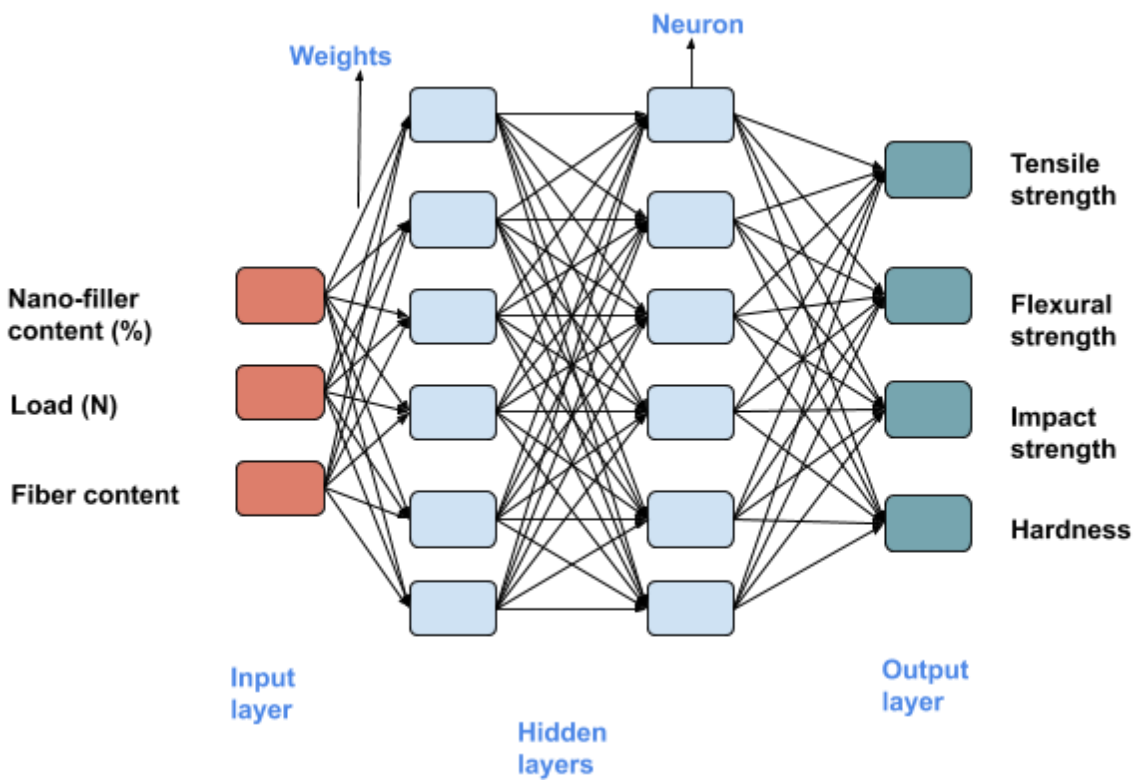

Figure 8. An example of an ANN model for predicting the properties of a composite material.

Atuanya et al. [62] studied the use of ANN approach to accurately predict the mechanical characteristics of recycled low density polyethylene composite reinforced with date palm wood fiber. In training the ANN model, ground fibres in varying weight percentages (wt \%) were used as input for different particle sizes while the output parameters consisted of the flexural modulus ultimate tensile strength, tensile modulus, flexural strength, hardness, and elongation. For validation of the training data set, test data were used to verify the model's accuracy. From their results, the correlation coefficients of all predictions with experimental data were more than 0.99 , which enabled them to conclude that artificial neural networks can be utilized successfully predicting the mechanical properties of natural fibres.

Other computational techniques that are classified as data-driven as opposed to modeldriven techniques include adaptive neuro-fuzzy inference system (ANFIS), genetic programming, and the gene expression programming algorithm. First introduced in 1985 by Takagi and Sugeno the ANFIS combines the power of fuzzy logic and ANN [71]. In genetic programming, GP is used essentially for carrying out optimization algorithms where computer algorithms are evolved to approximately model or solve complex problems [59,71]. 
The gene expression programming algorithm, GEP, is generally used to overcome the drawbacks of GP [59]. The ANFIS, GEP, and GP computational models have been used successfully to model the fatigue behavior of fiber reinforced by utilising the cyclic stress that form the S-N curves [59]. These models have been shown to be very powerful modeling tools for the nonlinear behavior of composite laminates subjected to constant amplitude loading [59].

\section{Conclusions}

Research progress on the mechanical behavior and performance of composite materials reinforced with natural fibers has been a topic of interest in the past decades. Computational methods, such as RoHM, FEA, and ANN, have been explored by researchers with the attempt of modelling and optimization of natural fiber composite materials for improved properties and utilization. The application modelling techniques in NFCs allows researchers to identify and isolate several parameters that have a significant effect on the resulting properties which are in turn used to carry out optimisation techniques. The application artificial intelligence methods for modelling and optimization of natural fiber composites has however received limited attention even though it has been proven to be the most successful new approach in modelling and optimization of composite materials. Computational techniques that take advantage of artificial neural networks offer a very promising formula to assess the limitations of predicting the mechanical characteristics of composite materials. However, to date, even though these methods have been proven to interpolate accurately the characteristics of materials using known data, there is limited evidence to support the predictive ability of these methods using unknown data. Perhaps therefore future research should focus on developing computational methods to address the research gap due to the increased growth in computational capabilities for solving complex problems.

Author Contributions: All authors have contributed equally. All authors have read and agreed to the published version of the manuscript.

Funding: This research received no external funding.

Acknowledgments: The authors appreciate the support of the Department of Mechanical, Energy and Industrial Engineering, Botswana International University of Science and Technology.

Conflicts of Interest: The authors declare no conflict of interest.

\section{Abbreviations}

The following abbreviations are used in this manuscript:

A Measure of fiber geometry, fiber distribution and fiber loading conditions

ANFIS Adaptive neuro-fuzzy inference system

ANN Artificial neural networks

CDM Continuum damage mechanics

AI Artificial Intelligence

FEA Finite Element analysis

GEP Gene expression programming

GP Genetic programming

KNN K-Nearest Neighbor

ML Machine Learning

NFC Natural fiber composite

NN Neural networks

PLA Poly(lactic acid)

PP Polypropylene

RoM Rule of mixture

RoHM Rule of hybrid mixture

SVM Support Vector Machines

UP Unsaturated Polyester 


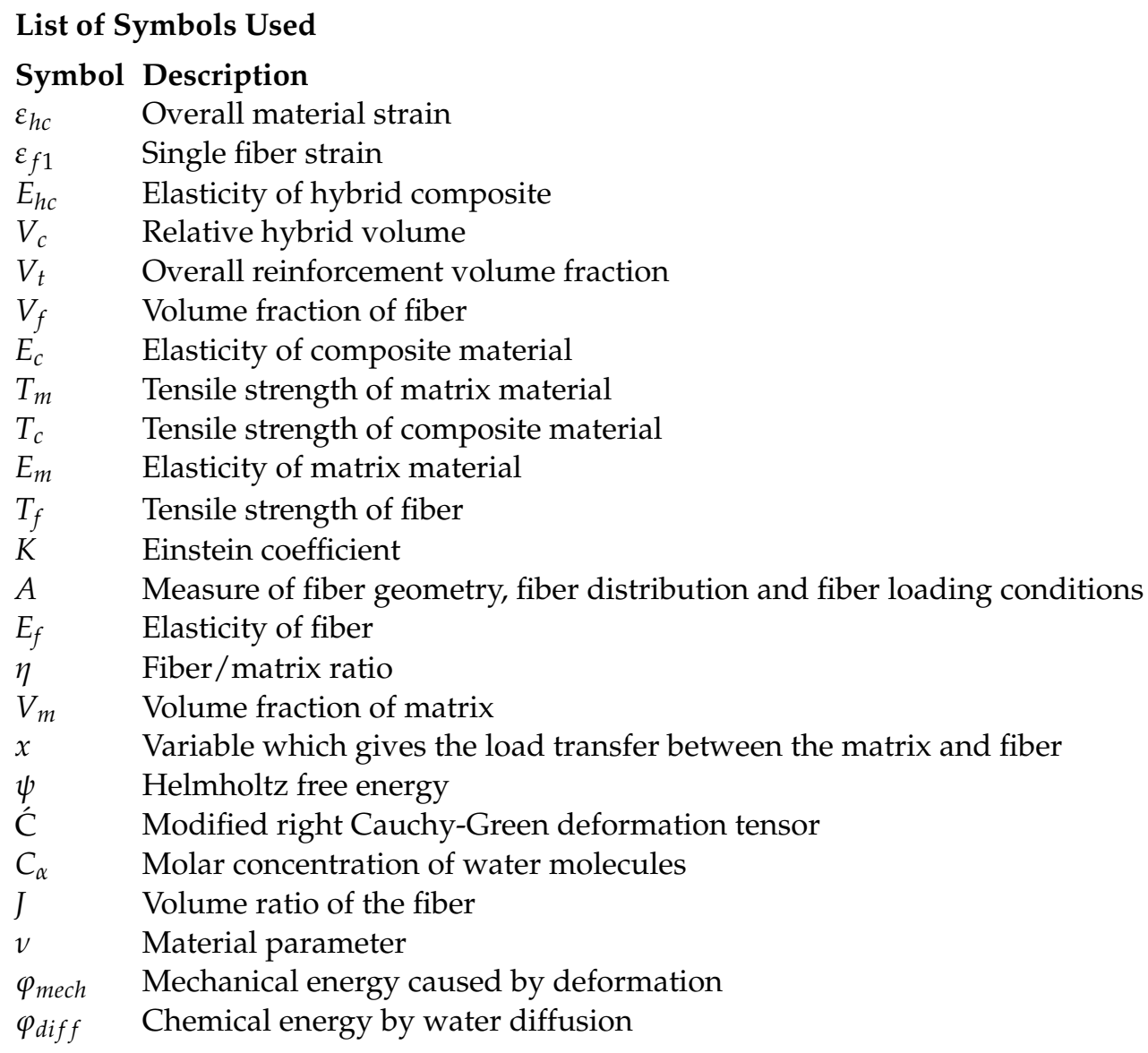

\section{References}

1. Kerni, L.; Singh, S.; Patnaik, A.; Kumar, N. A review on natural fiber reinforced composites. Mater. Today: Proc. 2020, $28,1616-1621$. [CrossRef]

2. Mochane, M.J.; Mokhena, T.C.; Mokhothu, T.H.; Mtibe, A.; Sadiku, E.R.; Ray, S.S.; Ibrahim, I.D.; Daramola, O.O. Recent progress on natural fiber hybrid composites for advanced applications: A review. Express Polym. Lett. 2019, 13, 159-198. [CrossRef]

3. Ramu, P.; Kumar, C.J.; Palanikumar, K. Mechanical Characteristics and Terminological Behavior Study on Natural Fiber Nano reinforced Polymer Composite-A Review. Mater. Today Proc. 2019, 16, 1287-1296. [CrossRef]

4. Otto, G.P.; Moisés, M.P.; Carvalho, G.; Rinaldi, A.W.; Garcia, J.C.; Radovanovic, E.; Fávaro, S.L. Mechanical properties of a polyurethane hybrid composite with natural lignocellulosic fibers. Compos. Part B Eng. 2017, 110, 459-465. [CrossRef]

5. Ude, A.U.; Eshkoor, R.A.; Azhari, C.H. Crashworthy characteristics of axial quasi-statically compressed Bombyx mori composite cylindrical tubes: Experimental. Fibers Polym. 2017, 18, 1594-1601. [CrossRef]

6. Ude, A.U.; Azhari, C.H. Lateral crashworthiness response of bombyx mori fibre/glass-fibre/epoxy hybrid composite cylindrical tubes-experimental. AIMS Mater. Sci. 2019, 6, 1227-1239. [CrossRef]

7. Mulenga, T.K.; Ude, A.; Vivekanandhan, C. Concise review on the mechanical characteristics of hybrid natural fibres with filler content. AIMS Mater. Sci. 2020, 7, 650-664. [CrossRef]

8. Thakur, V.K.; Voicu, S.I. Recent advances in cellulose and chitosan based membranes for water purification: A concise review. Carbohydr. Polym. 2016, 146, 148-165. [CrossRef]

9. Singha, A.S.; Thakur, V.K. Fabrication and Characterization of H. sabdariffa Fiber-Reinforced Green Polymer Composites. Polym. Technol. Eng. 2009, 48, 482-487. [CrossRef]

10. Motaleb, K.Z.M.A.; Milašius, R.; Ahad, A. Influence of Gamma Radiation on Mechanical Properties of Jute Fabric-Reinforced Polymer Composites. Fibers 2020, 8, 58. [CrossRef]

11. Trache, D.; Thakur, V.K.; Boukherroub, R. Cellulose Nanocrystals/Graphene Hybrids-A Promising New Class of Materials for Advanced Applications. Nanomaterials 2020, 10, 1523. [CrossRef] [PubMed]

12. Thakur, V.K.; Thakur, M.K.; Gupta, R.K. Review: Raw Natural Fiber-Based Polymer Composites. Int. J. Polym. Anal. Charact. 2014, 19, 256-271. [CrossRef]

13. Węcławski, B.T.; Fan, M.; Hui, D. Compressive behaviour of natural fibre composite. Compos. Part B Eng. 2014, 67, 183-191. [CrossRef]

14. Senthilkumar, K.; Saba, N.; Rajini, N.; Chandrasekar, M.; Jawaid, M.; Siengchin, S.; Alotman, O.Y. Mechanical properties evaluation of sisal fibre reinforced polymer composites: A review. Constr. Build. Mater. 2018, 174, 713-729. [CrossRef] 
15. Shireesha, Y.; Suresh, B.V.; Bahubalendruni, M.R.; Nandipati, G. Experimental Investigation on Mechanical Properties ofBiDirectional Hybrid Natural Fibre Composite (HNFC). Mater. Today Proc. 2019, 18, 165-174. [CrossRef]

16. Tisserat, B.; Montesdeoca, N.; Boddu, V.M. Accelerated Thermal Aging of Bio-Based Composite Wood Panels. Fibers 2020, 8, 32. [CrossRef]

17. Bambach, M.R. Direct Comparison of the Structural Compression Characteristics of Natural and Synthetic Fiber-Epoxy Composites: Flax, Jute, Hemp, Glass and Carbon Fibers. Fibers 2020, 8, 62. [CrossRef]

18. Parbin, S.; Waghmare, N.K.; Singh, S.K.; Khan, S. Mechanical properties of natural fiber reinforced epoxy composites: A review. Procedia Comput. Sci. 2019, 152, 375-379. [CrossRef]

19. Eshkoor, R.A.; Ude, A.U.; Sulong, A.B.; Zulkifli, R.; Ariffin, A.K.; Azhari, C.H. Energy absorption and load carrying capability of woven natural silk epoxy-triggered composite tubes. Compos. Part B Eng. 2015, 77, 10-18. [CrossRef]

20. Trache, D.; Thakur, V.K. Nanocellulose and Nanocarbons Based Hybrid Materials: Synthesis, Characterization and Applications. Nanomaterials 2020, 10, 1800. [CrossRef]

21. Ates, B.; Koytepe, S.; Ulu, A.; Gurses, C.; Thakur, V.K. Chemistry, Structures, and Advanced Applications of Nanocomposites from Biorenewable Resources. Chem. Rev. 2020, 120, 9304-9362. [CrossRef] [PubMed]

22. Hariprasad, K.; Ravichandran, K.; Jayaseelan, V.; Muthuramalingam, T. Acoustic and mechanical characterisation of polypropylene composites reinforced by natural fibres for automotive applications. J. Mater. Res. Technol. 2020, 9, 14029-14035. [CrossRef]

23. Khan, S.M.; Malik, S.A.; Gull, N.; Saleemi, S.; Islam, A.; Butt, M.T.Z. Fabrication and modelling of the macro-mechanical properties of cross-ply laminated fibre-reinforced polymer composites using artificial neural network. Adv. Compos. Mater. 2019, 28, 409-423. [CrossRef]

24. Nwobi-Okoye, C.C.; Uzochukwu, C.U. RSM and ANN modeling for production of Al 6351/ egg shell reinforced composite: Multi objective optimization using genetic algorithm. Mater. Today Commun. 2020, 22, 100674. [CrossRef]

25. Singha, A.S.; Thakur, V.K. Synthesis, Characterisation and Analysis of Hibiscus Sabdariffa Fibre Reinforced Polymer Matrix Based Composites. Polym. Polym. Compos. 2009, 17, 189-194. [CrossRef]

26. Manral, A.R.S.; Gariya, N.; Bansal, G.; Singh, H.P.; Rawat, A. Computational stress analysis of Chicken Feather Fibre (CFF) with Epoxy-Resin matrix composite material. Mater. Today Proc. 2020, 26, 2805-2810. [CrossRef]

27. Nwobi-Okoye, C.C.; Ochieze, B.Q.; Okiy, S. Multi-objective optimization and modeling of age hardening process using ANN, ANFIS and genetic algorithm: Results from aluminum alloy A356/cow horn particulate composite. J. Mater. Res. Technol. 2019, 8 , 3054-3075. [CrossRef]

28. Li, M.; Pu, Y.; Thomas, V.M.; Yoo, C.G.; Ozcan, S.; Deng, Y.; Nelson, K.; Ragauskas, A.J. Recent advancements of plant-based natural fiber-reinforced composites and their applications. Compos. Part B Eng. 2020, 200, 108254. [CrossRef]

29. Balasubramanian, K.; Rajeswari, N.; Vaidheeswaran, K. Analysis of mechanical properties of natural fibre composites by experimental with FEA. Mater. Today Proc. 2020, 28, 1149-1153. [CrossRef]

30. Saini, M.K.; Bagha, A.K.; Kumar, S.; Bahl, S. Finite element analysis for predicting the vibration characteristics of natural fiber reinforced epoxy composites. Mater. Today Proc. 2020. [CrossRef]

31. Behzad, T.; Sain, M. Finite element modeling of polymer curing in natural fiber reinforced composites. Compos. Sci. Technol. 2007, 67, 1666-1673. [CrossRef]

32. Pujari, S.; Ramakrishna, A.; Padal, K.B. Prediction of Swelling Behaviour of Jute and Banana Fiber Composites by using ANN and Regression Analysis. Mater. Today Proc. 2017, 4, 8548-8557. [CrossRef]

33. Summerscales, J.; Virk, A.S.; Hall, W. Enhanced rules-of-mixture for natural fibre reinforced polymer matrix (NFRP) composites (comment on Lau et al. in volume 136). Compos. Part B Eng. 2019, 160, 167-169. [CrossRef]

34. Summerscales, J.; Virk, A.S.; Hall, W. Fibre area correction factors (FACF) for the extended rules-of-mixtures for natural fibre reinforced composites. Mater. Today Proc. 2020, 31, S318-S320. [CrossRef]

35. Velmurugan, V.; Kumar, D.D.; Thanikaikarasan, S. Experimental evaluation of mechanical properties of natural fibre reinforced polymer composites. Mater. Today Proc. 2020, 16, 167. [CrossRef]

36. Chokshi, S.; Gohil, P.P.; Lalakiya, A.; Patel, P.; Parmar, A. Tensile strength prediction of natural fiber and natural fiber yarn: Strain rate variation upshot. Mater. Today Proc. 2020, 27, 1218-1223. [CrossRef]

37. Kumar, S.; Prasad, L.; Kumar, S.; Patel, V.K. Physico-mechanical and Taguchi-designed sliding wear properties of Himalayan agave fiber reinforced polyester composite. J. Mater. Res. Technol. 2019, 8, 3662-3671. [CrossRef]

38. Potluri, R.; Diwakar, V.; Venkatesh, K.; Reddy, B.S. Analytical Model Application for Prediction of Mechanical Properties of Natural Fiber Reinforced Composites. Mater. Today Proc. 2018, 5, 5809-5818. [CrossRef]

39. Tian, F.; Zhong, Z. Modeling of load responses for natural fiber reinforced composites under water absorption. Compos. Part $A$ Appl. Sci. Manuf. 2019, 125, 105564. [CrossRef]

40. Wu, T.; Yao, W.; Xu, C.; Li, P. A natural frequency degradation model for very high cycle fatigue of woven fiber reinforced composite. Int. J. Fatigue 2020, 134, 105398. [CrossRef]

41. Xiong, X.; Hua, L.; Miao, M.; Shen, S.Z.; Li, X.; Wan, X.; Guo, W. Multi-scale constitutive modeling of natural fiber fabric reinforced composites. Compos. Part A Appl. Sci. Manuf. 2018, 115, 383-396. [CrossRef]

42. Blanchard, J.M.F.A.; Mutlu, U.; Sobey, A.J.; Blake, J.I.R. Modelling the different mechanical response and increased stresses exhibited by structures made from natural fibre composites. Compos. Struct. 2019, 215, 402-410. [CrossRef] 
43. Wang, C.; Zuo, Q.; Lin, T.; Anuar, N.I.S.; Salleh, K.M.; Gan, S.; Yousfani, S.H.S.; Zuo, H.; Zakaria, S. Predicting thermal conductivity and mechanical property of bamboo fibers/polypropylene nonwovens reinforced composites based on regression analysis. Int. Commun. Heat Mass Transf. 2020, 118, 104895. [CrossRef]

44. Venkateshwaran, N.; Elayaperumal, A.; Sathiya, G.K. Prediction of tensile properties of hybrid-natural fiber composites. Compos. Part B Eng. 2012, 43, 793-796. [CrossRef]

45. Wang, K.F.; Wang, B.L. A mechanical degradation model for bidirectional natural fiber reinforced composites under hydrothermal ageing and applying in buckling and vibration analysis. Compos. Struct. 2018, 206, 594-600. [CrossRef]

46. Omrani, E.; Menezes, P.L.; Rohatgi, P.K. State of the art on tribological behavior of polymer matrix composites reinforced with natural fibers in the green materials world. Eng. Sci. Technol. Int. J. 2016, 19, 717-736. [CrossRef]

47. Pappu, A.; Thakur, V.K. Towards sustainable micro and nano composites from fly ash and natural fibers for multifunctional applications. Vacuum 2017, 146, 375-385. [CrossRef]

48. Jeyapragash, R.; Srinivasan, V.; Sathiyamurthy, S. Mechanical properties of natural fiber/particulate reinforced epoxy compositesA review of the literature. Mater. Today Proc. 2020, 22, 1223-1227. [CrossRef]

49. Vijayakumar, S.; Palanikumar, K. Mechanical Property Evaluation of Hybrid Reinforced Epoxy Composite. Mater. Today Proc. 2019, 16, 430-438. [CrossRef]

50. Dhanola, A.; Bisht, A.S.; Kumar, A.; Kumar, A. Influence of natural fillers on physico-mechanical properties of luffa cylindrica/ polyester composites. Mater. Today Proc. 2018, 5, 17021-17029. [CrossRef]

51. Islam, M.S.; Hasbullah, N.A.B.; Hasan, M.; Talib, Z.A.; Jawaid, M.; Haafiz, M.K.M. Physical, mechanical and biodegradable properties of kenaf/coir hybrid fiber reinforced polymer nanocomposites. Mater. Today Commun. 2015, 4, 69-76. [CrossRef]

52. Pickering, K.L.; Efendy, M.G.A.; Le, T.M. A review of recent developments in natural fibre composites and their mechanical performance. Compos. Part A Appl. Sci. Manuf. 2016, 83, 98-112. [CrossRef]

53. Cavalcanti, D.K.K.; Banea, M.D.; Neto, J.S.S.; Lima, R.A.A.; Da Silva, L.; Carbas, R.J.C. Mechanical characterization of intralaminar natural fibre-reinforced hybrid composites. Compos. Part B Eng. 2019, 175, 107149. [CrossRef]

54. Subasinghe, A.; Das, R.; Bhattacharyya, D. Study of thermal, flammability and mechanical properties of intumescent flame retardant PP/kenaf nanocomposites. Int. J. Smart Nano Mater. 2016, 7, 202-220. [CrossRef]

55. Chollakup, R.; Smitthipong, W.; Kongtud, W.; Tantatherdtam, R. Polyethylene green composites reinforced with cellulose fibers (coir and palm fibers): Effect of fiber surface treatment and fiber content. J. Adhes. Sci. Technol. 2013, 27, 1290-1300. [CrossRef]

56. Pappu, A.; Pickering, K.L.; Thakur, V.K. Manufacturing and characterization of sustainable hybrid composites using sisal and hemp fibres as reinforcement of poly (lactic acid) via injection moulding. Ind. Crop. Prod. 2019, 137, 260-269. [CrossRef]

57. Saw, S.K.; Akhtar, K.; Yadav, N.; Singh, A.K. Hybrid Composites Made from Jute/Coir Fibers: Water Absorption, Thickness Swelling, Density, Morphology, and Mechanical Properties. J. Nat. Fibers 2014, 11, 39-53. [CrossRef]

58. Boopalan, M.; Niranjanaa, M.; Umapathy, M.J. Study on the mechanical properties and thermal properties of jute and banana fiber reinforced epoxy hybrid composites. Compos. Part B Eng. 2013, 51, 54-57. [CrossRef]

59. Vassilopoulos, A.P.; Georgopoulos, E.F. Computational intelligence methods for the fatigue life modeling of composite materials. In Fatigue Life Prediction of Composites and Composite Structures; Woodhead Publishing: Cambridge, UK, 2020; pp. 349-383.

60. Kashyap, S.; Nath, D.; Das, D. Characterization, weathering and modeling of natural fibre based composites. Mater. Today Proc. 2020, 26, 963-971. [CrossRef]

61. Venkateshwaran, N.; Elayaperumal, A. Modeling and evaluation of tensile properties of randomly oriented banana/epoxy composite. J. Reinf. Plast. Compos. 2011, 30, 1957-1967. [CrossRef]

62. Krishnan, K.A.; Anjana, R.; George, K. Effect of alkali-resistant glass fiber on polypropylene/polystyrene blends: Modeling and characterization. Polym. Compos. 2014, 37, 398-406. [CrossRef]

63. Arrakhiz, F.Z.; Hamou, K.B.; Erchiqui, F.; Hammiche, D.; Kaddami, H. Development and characterization of hybrid composite laminate based on luffa and glass fibers. Mater. Today Proc. 2020. [CrossRef]

64. Pan, Y.; Zhong, Z. Relative humidity and temperature dependence of mechanical degradation of natural fiber composites. Sci. China Ser. G Physics, Mech. Astron. 2016, 59, 664603. [CrossRef]

65. Tian, F.; Zhong, Z.; Pan, Y. Modeling of natural fiber reinforced composites under hygrothermal ageing. Compos. Struct. 2018, 200, 144-152. [CrossRef]

66. Karakoti, A.; Tripathy, P.; Kar, V.R.; Jayakrishnan, K.; Rajesh, M.; Manikandan, M. Finite element modeling of natural fiber-based hybrid composites. In Modelling of Damage Processes in Biocomposites, Fibre-Reinforced Composites and Hybrid Composites; Woodhead Publishing: Cambridge, UK, 2019; pp. 1-18.

67. Kern, W.T.; Kim, W.; Argento, A.; Lee, E.C.; Mielewski, D.F. Finite element analysis and microscopy of natural fiber composites containing microcellular voids. Mater. Des. 2016, 106, 285-294. [CrossRef]

68. Sowmya, C.; Ramesh, V.; Karibasavaraja, D. An Experimental Investigation of New Hybrid Composite Material using Hemp and Jute Fibres and Its Mechanical Properties through Finite Element Method. Mater. Today Proc. 2018, 5, 13309-13320. [CrossRef]

69. Ang, J.Y.; Majid, M.A.; Nor, A.M.; Yaacob, S.; Ridzuan, M.J.M. First-ply failure prediction of glass/epoxy composite pipes using an artificial neural network model. Compos. Struct. 2018, 200, 579-588. [CrossRef] 
70. Raschka, S.; Mirjalili, V. Python Machine Learning: Machine Learning and Deep Learning with Python, Scikit-Learn, and TensorFlow 2, 3rd ed.; Packt Publishing, Limited: Birmingham, UK, 2019; ISBN 9781789955750.

71. Takagi, T.; Sugeno, M. Fuzzy identification of systems and its applications to modeling and control. In IEEE Transactions on Systems, Man, and Cybernetics; IEEE: Piscataway, NJ, USA, 1985; pp. 116-132. [CrossRef] 